\title{
O SISTEMA METAFÍSICO DE SCHOPENHAUER E A METAPSICOLOGIA DE FREUD: ENCONTROS E DESENCONTROS
}

\author{
Mateus Freitas Barreiro \\ Universidade Estadual Paulista - UNESP - Brasil \\ Alonso Bezerra Carvalho \\ Universidade Estadual Paulista - UNESP - Brasil \\ $*$
}

\begin{abstract}
Resumo
O presente artigo visa analisar as tramas e tensões entre o surgimento da psicanálise de Freud em contato com a filosofia de Schopenhauer. Com a publicação dos escritos psicanalíticos de Freud em sua fase metapsicológica, o psiquismo começou a ser trabalhado por ele sob uma nova perspectiva, rompendo assim com a psicologia clássica de sua época. Por sua vez, e comparativamente, o sistema metafísico adotado por Schopenhauer, visava responder as teorizações sobre um princípio básico que rege o universo, independente de uma utilização necessariamente prática. Embora a psicanálise e a filosofia tenham diferentes objetivos, ainda não se conhece com profundidade a contribuição da filosofia na construção da teoria psicanalítica desenvolvida por Freud, principalmente, no que tange aos encontros e desencontros que o prefixo meta tem na metafísica preconizada por Schopenhauer e na metapsicologia de Freud.
\end{abstract}

Palavras-chave: Schopenhauer, Freud, metafísica, metapsicologia.

\section{Considerações iniciais}

A aproximação da psicanálise com a filosofia tem sido feita sempre tomando como referência que ambas propõem-se atingir diferentes objetivos, mesmo que elas estejam entrelaçadas por alguns conceitos referentes ao avanço do conhecimento. Quando se trata desta interlocução de saberes, abarcando a relação de Freud com a filosofia, na maioria das vezes o tema se remete à ambivalência de Freud em relação à filosofia, ora distanciando-se dela e criticando-a por achar seu funcionamento parecido a um delírio, ora dela aproximandose em outras circunstâncias, reverenciado pelo seu antigo desejo de ser filósofo.

Podemos perceber que na Conferência 35 de Novas Conferências, Freud discorre acerca da filosofia, ao propor seu ponto de vista a respeito da diferença entre a filosofia e a psicanálise: para ele, a primeira consiste em uma construção intelectual que visa resolver de modo unitário todos os problemas existenciais a partir de uma hipótese, na qual, por 
consequência, nenhuma questão resta aberta, tendo o seu lugar determinado (FULGENCIO, 2003, p.18).

Nesse sentido, para Freud, a filosofia não solucionava problemas da prática psicanalítica, ou se até mesmo resolveria outras questões relevantes para o campo científico. Poderia se perguntar se tais posicionamentos de Freud em relação à filosofia não se derivavam de sua atuação marcada pela prática psicanalítica, mais do que pela intenção em construir um sistema de pensamento. Sobre esse questionamento da relação de Freud com a filosofia, Fulgencio (2003, p.19) faz um comentário construtivo a respeito da ambiguidade de Freud em relação à filosofia. Ele sugere que esta ambiguidade não se referia à sua atuação eminentemente prática, nem tampouco ao seu posicionamento de se colocar sempre na posição de cientista, mas em buscar solucionar problemas empíricos que exigiam especulação. O objetivo final de Freud era resolver tais problemas e não se ater à formulação de uma "visão de mundo", nem de verdades cristalizadas sobre o mundo e o homem (FULGENCIO, 2003, p.19).

Diante do acima exposto, nosso posicionamento neste artigo, reitera que é equivocado traçar um paralelo entre filosofia e psicanálise enfatizando um eventual reducionismo da psicanálise em relação à filosofia ou ignorando quaisquer influências da filosofia em relação à psicanálise. Pretendemos, isto sim, entender a existência de continuidade entre os pensamentos de Schopenhauer e Freud, embora cada um deles possua características próprias e critérios específicos de validação do conhecimento nos seus respectivos campos de pesquisa. Visto que Schopenhauer foi um dos filósofos mais citados por Freud serão tratados, neste artigo, os encontros e desencontros que dizem respeito aos fundamentos metodológicos que embasaram as teses de cada autor.

\section{O empirismo de Schopenhauer: aproximações iniciais com a psicanálise}

Uma das primeiras referências à similitude entre o texto de Freud e o de Schopenhauer foi feita em 1926, através de um artigo escrito por Otto Juliusberger, médico berlinense, participante de uma das muitas sociedades schopenhauerianas existentes na época. Juliusberger sustentou que Freud empregava em seu discurso psicanalítico temáticas e pensamentos já antecipados nas obras de Schopenhauer. De fato, a conexão de Freud com o sistema metafísico schopenhaueriano se estabelecia por múltiplos pontos e formas de contato. Primeiramente, quando Freud estava desenvolvendo os fundamentos da teoria psicanalítica, o pensamento de Schopenhauer era marcante ao final do século XIX e muito popular nos meios 
frequentados por Freud. Zentner (1995) analisa os dados biográficos resgatados por Willian McGrath, em que descreve a inserção de Freud em um grupo composto por alunos, autodenominados de Clube de Leitura dos Estudantes Alemães de Viena entre os anos de 1873-1878, sendo Schopenhauer um dos principais autores estudado neste grupo (ZENTNER, 1995, p.463-64). O pensamento filosófico de Schopenhauer caminhou por múltiplas vias identificáveis e não identificáveis que transitaram no pensamento de Freud, que também já expressava outras ideias e conhecimentos advindos de sua prática psicanalítica. Em 1920, no prefácio à quarta edição dos Três Ensaios, Freud lembrou a seus leitores, com uma relativa satisfação indômita, que o rebelde e independente não era ele, e sim o filósofo alemão Arthur Schopenhauer, que "havia confrontado a humanidade, há algum tempo, com a amplitude na qual suas ações são determinadas por impulsos sexuais" (GAY, 2002, p.149). Pode-se então dizer que o pensamento de Schopenhauer sobre as ações que mobilizam a conduta humana tem como fio condutor o pressuposto de que existem vontades primárias à natureza, na qual o intelecto é apenas um instrumento racional do querer. A abstração conceitual que leva a vontade a ser concebida como uma coisa em si, e a vinculação da representação em uma categoria da razão, como veremos, fazem com que essas formulações de Schopenhauer sejam erroneamente atribuídas ao âmbito exclusivo das especulações metafísicas. Com efeito, a formação naturalista de Schopenhauer pode ter sido uma das causas de que o conteúdo de sua metafísica seja algo imanente à realidade empírica, e não simplesmente uma construção ontológica desvinculada do plano concreto.

Interessado pela questão da sanidade e doença do homem, no outono de 1809 Schopenhauer escolheu estudar medicina na Faculdade de Göttingen. Passados três ou quatro meses, apesar de seu gosto pela medicina e ciências naturais, deixou aquela faculdade porque não suportava a limitação do organicismo iluminista e por não ter nenhum espaço para pesquisas de temáticas variadas; portanto, pensou que deveria tornar-se filósofo. Desiludido com as aulas de Fichte, que expressavam uma concepção idealista sobre as inter-relações entre genialidade e loucura, Schopenhauer acabou decidindo fazer sua própria pesquisa na solidão e liberdade, mas não fechado em seu próprio quarto, e sim estando sempre em contato direto com sujeitos da ala psiquiátrica (IANNACO, 1998, p.19-20). O jogo idealista e abstrato de palavras que não relacionam os conceitos com a realidade não eram métodos realísticos para Schopenhauer, conforme reconhece:

Me alegra em particular o fato de já estar habituado, assim tão cedo (...) a não me contentar com o simples nome das coisas e preferindo, sobre o mar das palavras, a 
consciência nascida da observação. Por este motivo nunca corri o risco em consequência de tomar as palavras por coisas (SCHOPENHAUER, 2004, p.13).

Fica evidente que Schopenhauer, por um lado, fez algumas objeções aos estudos da medicina de sua época, mas em contrapartida, não deixou de pensar filosoficamente a partir de uma perspectiva empírica. Essa perspectiva confere amplitude e profundidade ao conceito schopenhaueriano de loucura, que representa um dos pontos fundamentais da experiência empírica que Schopenhauer teve para formular seu próprio sistema filosófico.

Primordialmente, a ideia schopenhaueriana sobre a loucura aparenta ter raízes apenas em especulações filosóficas, por se tratar de uma teoria não concisa e devidamente sistematizada. Contudo, a partir de documentos históricos resgatados por Zentner (1995) foi possível constatar que o fator que contribuiu para Schopenhauer fundamentar seu pensamento acerca da loucura, deu-se por meio de sua experiência empírica, ao entrar em contato com pacientes da ala psiquiátrica do hospital Charité em Berlim, que o filósofo frequentou desde 1811. Em O Mundo como Vontade e Representação, é possível encontrarmos indícios deste contato de Schopenhauer com pacientes do hospital Charité, quando ele afirma: "visitei frequentemente casas de alienados e encontrei aí sujeitos de um incontestável valor; o seu gênio manifestava-se distintamente através da sua loucura; mas neles a loucura tinha permanecido completamente dominante" (SCHOPENHAUER, 2004, p. 201).

$\mathrm{O}$ mecanismo da loucura ocorre quando um acontecimento extremamente árduo e angustiante para o indivíduo chega a atingir o seu limiar de tolerância, e como resposta a sua natureza recorre à loucura como "último recurso" para cessar estas dores. Assim, "o espírito torturado rompe, por assim dizer, o fio da sua memória" (SCHOPENHAUER, 2004, p.203). Esta amnésia parte de um conflito entre a vontade e o intelecto e, se algum conteúdo for doloroso para a vontade, esta evita que o intelecto tome consciência de tal conteúdo. Deste modo, na concepção schopenhaueriana, a loucura teria funcionalmente um papel diminutivo em conflitos análogos aos postulados por Freud. Deste modo, sintomaticamente, a doença atuaria por intermédio de uma necessidade mental para poder esquecer lembranças dolorosas, que tem como seu objetivo eliminar angústias.

Para Schopenhauer (2004, p.203), a loucura emana da necessidade de esquecer experiências dolorosas adjacentes da realidade, tais como "violentas dores morais" e “acontecimentos terríveis" (SCHOPENHAUER, 2004. p.203). Por vias transversas, o pensamento sobre a loucura se coaduna com o conceito de recalque de Freud, uma vez que este concebe que a essência do recalque consiste em afastar da consciência um determinado devaneio, evento ou percepção que seja desprazerosa para o indivíduo (FREUD, 1996, vol.6, 
p.15-16). Ambos os pensadores acreditam que o inconsciente inclui mecanismos dissipadores de memórias traumáticas. Não obstante, o empirismo de Freud era fundamentado no positivismo de sua época. A teoria psicanalítica buscou resolver um problema do estudo empírico e do tratamento das neuroses, então a metapsicologia é formulada com o objetivo de pesquisar e descrever os distúrbios da vida psíquica consciente, observados na prática clínica (LOPARIC, 2001, p.4). A partir destas observações, Freud faz uso de seu método interpretativo para desvelar os conteúdos inconscientes.

A conversão das representações em uma sintomatologia apresentada na forma de doença seria uma reação para preservar a individualidade. Na visão freudiana, utilizam-se mecanismos de defesa como uma resposta natural da estrutura psíquica para a eliminação de tal angústia. Esta reação poderia emergir através de um ganho primário, em que a redução da tensão e do conflito dar-se-ia através de uma doença neurótica ou histérica. Todo este processo, que tem sua chave no recalque, ocorre quando um conteúdo representativo oriundo do consciente se desloca para o inconsciente e, como consequência, converte-se em uma patologia.

Na perspectiva freudiana, a estruturação do conceito de defesa está vinculada a uma hipótese sobre o funcionamento mental, que é a de uma perspectiva representacional do psiquismo. Sua dinâmica se baseia em um investimento energético, a energia das forças por trás das representações mentais que se desloca. Os impulsos com maior quantidade de energia são mais difíceis de reprimir do que os que possuem menor quantidade de energia, porém, podem ser reprimidos caso as contra-forças sejam equivalentes quanto à quantidade de energia.

O conceito de loucura, igualmente ao recalque, se constituiu através de observações em sujeitos cujas experiências de vidas lhes proporcionaram a formação de uma subjetividade singular. Tal subjetividade foi interpretada como uma enfermidade para aquele tempo, fazendo com que o estudo fosse voltado para entender os processos que eram responsáveis pela formação de um sintoma. Tanto na etiologia da loucura quanto no recalque, a função é a de resgatar a integridade do eu.

É sabido que a noção de loucura foi desenvolvida por Schopenhauer através da sua experiência empírica no hospital Charité em Berlim, bem como a construção de sua filosofia, que apresenta uma relação direta com a realidade:

Em contrapartida, minha filosofia começou com a proposição de que há causas e consequências somente no mundo e como pressupostos seus, pois o princípio da razão, em seus quatro aspectos, é apenas a forma mais geral do entendimento, mas 
só neste último reside o mundo objetivo como verdadeiro locus mundi. (SCHOPENHAUER, 2007, p.186).

Constata-se assim, que a metafísica de Schopenhauer necessita do mundo objetivo para não transcender os limites da validação das estruturas do conhecimento, pois se a metafísica não tivesse uma relação com a realidade, seria algo fantasmagórico, pois o conceito de loucura seria um conceito sem vínculos com a realidade formal.

Contudo, a metafísica de Schopenhauer não estava inserida em contexto científico como o positivismo de Freud, mas ainda assim ela operou no interior do discurso freudiano, ao auxiliá-lo a criar conceitos que tratam sobre os impulsos inconscientes. Embora Schopenhauer tenha constatado os fenômenos por meio da experiência, ao chegar ao conhecimento da coisa em si, foi preciso formular conceitos metafísicos que permitissem entender como ocorreria a objetivação da noção de loucura em uma perspectiva mental.

Em sua principal obra, O Mundo como Vontade e Representação, Schopenhauer transita por diversos segmentos do conhecimento, para desenvolver o conceito de vontade que diz respeito a uma raiz metafísica do mundo. Ao discorrer sobre a questão da vontade, pudemos perceber que Schopenhauer concebe-a como a coisa em si, representando a essência subjacente ao mundo. Por conseguinte, o mundo das representações ou fenomênico pode ser considerado vontade.

A vontade humana é o fenômeno mais claro da vontade (Wille), porém, na vontade humana há participação do intelecto. Schopenhauer irá transpor um paralelo entre vontade e intelecto, em que o intelecto consciente e racional está subordinado a uma vontade inconsciente e volitiva. Partilhando também deste olhar em seu aspecto dual, Freud irá transcrever esta dualidade em consciente-inconsciente, uma oposição entre o cognoscívelincognoscível. Ambos os autores, postulam em suas teorias instâncias que descrevem o conjunto de conteúdos que não participam do campo composto pela consciência. Freud denomina esta instância de inconsciente, que se dinamiza através de um impulso que se situa no interior da psíquê, onde há um estímulo corporal como fonte de excitação; em Schopenhauer esta mesma instância é denominada vontade, em que o corpo é ponto de objetivação da vontade e de convergência com a representação.

Embora o homem ocupe o topo da pirâmide, este tem apenas a capacidade de pressupor a existência da vontade, mas ela não tem início ou encerramento, é a coisa em si sempre presente. Seu mínimo ou máximo relativos poderia ser entendido como a variação dos graus e formas de sua objetivação, mas para pensar sua potência é necessário pensar primeiramente em um todo para poder figurar a imagem da vontade no pensamento enquanto 
unidade. A justificativa para o conceito de vontade ser qualitativamente uno, é que a "unidade deve reconhecer-se pelo aspecto de parentesco íntimo que todas as suas manifestações têm" (SCHOPENHAUER, 2004, p.152). É importante notar que o caráter uno da vontade se transpõe em vários modos de objetivação por meio das formas intuitivas como espaço e tempo, que estão presentes no mundo fenomênico, pois a própria realidade empírica serve de referência para concepção do uno. Assim, a vontade nutre um caráter de unicidade, o que leva a concluir que Schopenhauer visou tornar à vontade um conceito-princípio, e, a partir desta infinidade, comprovar sua elementaridade por meio de analogias. Vejamos de perto alguns exemplos em que Schopenhauer descreve a vontade no mundo empírico através de seu raciocínio per analogiam:

Se olharmos atentamente, se virmos o ímpeto poderoso, irresistível, com que as águas se precipitam nas profundezas, a tenacidade com que o imã se volta sempre para o polo norte, a atração que ele exerce sobre o ferro, a violência que cresce com os obstáculos, como os desejos humanos; se considerarmos a rapidez com que se opera a cristalização, a regularidade dos cristais, que resulta unicamente de um movimento de diversas direções bruscamente parado e submetido, na sua solidificação, a leis rigorosas; se observarmos o discernimento com que os corpos privados dos laços da solidez e postos em liberdade no estado fluido se procuram ou se evitam, se unem ou se separam; e, enfim, notarmos como um peso de que o nosso corpo impede a atração para o centro da terra comprime e pesa continuadamente sobre este corpo, de acordo com a lei da atração (SCHOPENHAUER, 2004, p.126127).

Dentre estes exemplos descritos por Schopenhauer, e que podem ser visualizados na natureza, e movem os corpos inorgânicos, encontramos em meio a essas observações, diferentes alegações por base em analogias que perpassam princípios orgânicos, físicos e as vontades humanas, em que o corpo representa o ponto de convergência máximo da objetivação da vontade. A princípio, com o raciocínio analógico, o objetivo é constatar a onipresença da vontade no mundo fenomênico, e para isso Schopenhauer vale-se de explanações figurando à vontade entre os meios vegetais, fenômenos físicos, arte e quaisquer outras vias passíveis de identificação.

A vontade é onipresente no mundo, mas seus atos de objetivação diferem radicalmente em intensidade. No menor grau da vontade encontramos as manifestações de toda natureza inorgânica, estas são as forças primeiras que concerne à física e à química desvelar e conhecer suas leis. Na medida em que eleva sua intensidade, a vontade passa a atuar também no reino vegetal, onde a sua conexão com os fenômenos já não é mais uma causa, mas uma excitação 
(SCHOPENHAUER, 2004, p.158). O conceito de vontade enquanto estava se constituindo fez Schopenhauer acoplar uma exemplificação da vontade a outra, reunindo seus sedimentos para formar um todo e simultaneamente cada sedimento possui sua parte neste todo.

Raikovic (1996, p.34) sustenta que Freud empregou o mesmo raciocínio analógico, buscando um fim semelhante ao de Schopenhauer, esforçando-se por expor que o psiquismo individual encerra-se em um mesmo fundamento, o inconsciente, e para demonstrar a existência de um mesmo inconsciente em cada um, em cada aparelho psíquico, é necessário, primeiramente, ter provado a existência de uma consciência em cada indivíduo (RAIKOVIC, 1996, p.34).

Uma das principais influências que inspirou Schopenhauer na utilização da analogia em suas pesquisas foi nas disciplinas de Johann Friedrich Blumenback, seu primeiro professor na faculdade de medicina, que ensinou sobre a função do organismo na compreensão da natureza e o uso da analogia nas ciências (PRADO, 2015, p.52). O método analógico de Schopenhauer tem a função de fundamentar as hipóteses sobre a essência do mundo em comparação à estrutura corpórea e mental do ser humano. Nessa correlação entre a coisa em si e a objetivação da vontade na ação do homem, há uma diferença de natureza, mas não em essência como sustenta Schopenhauer:

A vontade é a substância íntima, o núcleo tanto de toda coisa particular, como de conjunto; é ela que se manifesta na força natural cega; ela encontra-se na conduta racional do homem; se as duas diferem tão profundamente, é em grau e não em essência (SCHOPENHAUER, 2004, p.119).

Em Justificação do Conceito de Inconsciente, Freud parece referir-se a Schopenhauer quando discute a questão da analogia da consciência em objetos inanimados, conforme suas palavras:

Essa inferência (ou essa identificação) foi anteriormente estendida pelo ego a outros seres humanos, a animais, a plantas, a objetos inanimados e ao mundo em geral, e revelou-se útil enquanto sua semelhança com o ego individual era esmagadora; contudo, tornou-se menos digna de confiança na medida em que a diferença entre o ego e esses 'outros' aumentou. Hoje em dia, nosso julgamento crítico já se põe em dúvida quanto à questão da existência de consciência nos animais; recusamo-nos a admiti-la nas plantas e encaramos como misticismo a suposição de sua existência nas coisas inanimadas. (FREUD, 1996, vol.14, p.174). 
Como foi constatado, o procedimento analógico de Schopenhauer a que Freud provavelmente se referiu, se tratava de uma analogia entre fenômenos que apresentam diferentes graus de objetivação da vontade. Quanto mais complexo o organismo, maior será a necessidade do intelecto para mediar à volição da vontade. Mas em Freud o procedimento analógico não foi utilizado para comprovar a existência da consciência em plantas, animais e coisas inanimadas, pois na psicanálise isto seria uma suposição mística. Para a psicanálise, o inconsciente é uma instância diferente do mundo físico, mas compartilha o pressuposto de universalidade no campo da psíquê, na medida em que para supor a existência de um inconsciente é preciso ter comprovado a existência de uma consciência em cada indivíduo.

Primordialmente, Freud sempre se mostrou preocupado em não se afastar do viés clínico, pois a psicanálise visou compreender os processos e intervir neles. Contudo, apenas as observações empíricas não eram suficientes para descrever a dinâmica dos processos inconscientes. Freud desenvolveu a metapsicologia para ir além da psicologia positivista de seu tempo, e organizar as observações clínicas em termos de funcionamento dos processos psíquicos. Em Freud as analogias contribuíram com a metapsicologia no sentido de auxiliar na constatação ou na comparação de determinados fenômenos que não são diretamente observáveis, mas que precisam de conceitos que vão além da experiência imediata. Estamos de acordo quanto à estrutura de pensamento per analogiam utilizada por ambos autores, mas acrescentemos ainda, que por conta do empirismo presente do sistema psicanalítico, Freud recorreu a outras técnicas para incorporar seu conceito de inconsciente, tal como atos falhos, sonhos e outros, que foram devidamente sistematizados com o intuito de aplicá-los no estritamente campo clínico.

Foi por via da metapsicologia que a problemática fundamental da psicanálise foi transposta para a filosofia. Este sistema consistia em três níveis (o tópico, o dinâmico e o econômico) com função de explicitar os fenômenos mentais e os lugares psíquicos em que estariam ocorrendo (BIRMAN, 2003, p. 43). O ponto de vista tópico consiste em delinear os registros psíquicos em que aquela experiência estaria acontecendo e que tipo de representação estaria em evidência. Nesta configuração, o psiquismo seria como se fosse um aparelho, em que seria possível visualizá-lo e figurá-lo como se fosse um telescópio, um microscópio ou um objeto com características similares, criando assim a possibilidade de assimilar e diferenciar as instâncias psíquicas que compõem este aparelho, sem necessariamente identificá-lo com alguma região anatômica. O nível dinâmico diz respeito às pulsões (forças psíquicas) básicas em conflito, são forças motoras originárias do funcionamento da vida psíquica; o econômico é o pressuposto de uma energia libidinal que é entendida em sua forma 
quantitativa, que move as pulsões e os investimentos no objeto de desejo (FULGENCIO, 2003, p.145).

A suposição tópica para Freud (1996, v.14, p.201) a respeito da relação entre o inconsciente e consciente é estritamente remetida a uma separação topográfica entre o sistema Ics. e Cs., e também é possível que uma ideia possa existir de forma simultânea em dois locais do mecanismo mental (FREUD, 1996, v.14, p.201). Quando Freud desenvolveu a primeira tópica, as nomenclaturas $C s$ (consciente), Pcs (pré-consciente) e Ics (inconsciente) eram utilizadas na descrição dos pensamentos que não eram compostos pelo campo da consciência; viu-se que nesta perspectiva topográfica ocorre uma separação dual entre o inconsciente e consciente, uma primária e a outra secundária. Já na segunda tópica, os sistemas Cs, Pcs e Ics são relacionados às instâncias id, ego e superego. Nessa abordagem, os modelos psíquicos contêm forças que se deslocam entre as instâncias psíquicas; esta descrição de funcionamento do aparelho psíquico em que as forças transitam de uma estrutura para outra é uma tentativa freudiana de ampliar a mobilidade entre o consciente e inconsciente. A dualidade fica mais evidente nos termos explicitados pelo próprio Freud, na primeira hipótese, a topográfica, que está estreitamente vinculada a uma separação entre os sistemas Ics. e Cs. Continua Freud (1969, vol.14, p.18) argumentando também sobre a possibilidade de que uma ideia possa existir simultaneamente em dois lugares em um mecanismo mental. (FREUD, 1969, vol.14, p.18). Na primeira tópica Freud se aproxima mais do olhar dualista de Schopenhauer, em que o consciente-inconsciente diz respeito a uma oposição entre o cognoscível-incognoscível. Não obstante, é preciso destacar que o consciente e inconsciente é intermediado pelo préconsciente, ao passo que em Schopenhauer, a representação é ponto de convergência entre a vontade e o intelecto.

Nos primeiros textos de Freud, há uma forte convicção de que o pensamento causal e seus fenômenos podem ser investigados pelas ciências naturais, que também são aplicados aos fenômenos psíquicos (GOMES, 2003, p.123). Inicialmente, Freud procurava exclusivamente por um único trauma na histeria que pudesse explicar sua patologia, e, trazendo esta recordação para a consciência, seria possível curar a enfermidade. Mas com a metapsicologia constata-se que Freud entendia que um mesmo efeito poderia ter diversas causas, e são vários os fatores da vida de uma pessoa que contribuem para estruturar sua psíquê de uma determinada maneira. Com este entendimento de múltiplas causas, acaba se tornando ainda mais complexa a tarefa do analista em desvelar a construção de um significado subjacente a um transtorno psíquico. Assim, não existe nada sem significado, arbitrário ou de causalidade 
nas aparições psíquicas, mas há causas múltiplas para o mesmo efeito (FREUD, 1996, vol.6, p.36,).

Embora a metapsicologia freudiana utilize o procedimento especulativo para dar maior margem de alcance conceitual à ideia de causalidade, não se pode esquecer que por se tratar de um contexto clínico, a questão da causalidade deverá ser interpretada de forma perspicaz pelo analista. Com a segunda tópica, a interlocução do inconsciente com as outras estruturas psíquicas, como id, ego e superego torna a visão dual entre a consciência e inconsciência menos evidente. O superego não consegue obedecer à maioria das reivindicações por parte das pulsões advindas do id, porém, estas estruturas são complementares, uma não anula a outra, embora esta relação seja predominantemente conflitiva. Em termos sintéticos, a correspondência da perspectiva metapsicológica com a metafísica de Schopenhauer é proveniente do paralelo entre o intelecto-ego e a vontade-id.

A contribuição teórica do método especulativo não compõe para Freud uma ciência da natureza do psiquismo e da psíquê, e também não é o fundamento último da psicanálise, mas funciona como uma "supra-estrutura" especulativa que compõe um conjunto de "convenções" - "construções auxiliares", acopladas com a finalidade de sua utilização metodológica e heurística na organização do material proveniente da clínica (“empírico”), na procura de novos resultados clínicos (LOPARIC, 2001, p.10). Por outro lado, os conceitos metafísicos schopenhauerianos como a vontade, não são utilizados como convenções, pois Schopenhauer visou reunir preposições para solidificar seus conceitos, e fortalecê-los por meio de analogias, baseadas em suas observações empíricas. Também são de ordem especulativa, devido à vontade envolver uma essência (Innerstes Wesen) em torno das regras que regem o universo e os fluxos volitivos comum entre todas as categorias de fenômenos, conforme esclarece Schopenhauer:

\footnotetext{
A essência do mundo e o verdadeiro substrato dos fenômenos, àquilo que está liberto de toda mudança e, por conseguinte, é conhecido como uma verdade igual para todos os tempos, em uma palavra, as ideias, as quais constituem a objetividade imediata e adequada da coisa em si (SCHOPENHAUER, 2004, p.194).
}

Nessa passagem, pode se constatar que a essência do mundo (vontade), está circunscrita à infraestrutura da filosofia de Schopenhauer, pois não há uma intenção de que este conceito deva ser uma especulação provisória, pois é construída uma ontologia que designa uma "verdade igual para todos os tempos". 
A possibilidade de orientação do pensamento que a especulação ocupa dentro das estruturas conceituais em Freud-Schopenhauer os distanciam. Em Freud, a especulação só se justifica por auxiliar a organizar os dados empíricos e não por corresponder necessariamente a um possível elemento dos fenômenos (FULGENCIO, 2003). A questão da realidade do mundo exterior, só entra em cena para discutir o mundo psíquico, em que o conceito de inconsciente possivelmente foi formulado com o auxílio de pressupostos filosóficos. Enquanto a especulação schopenhaueriana visa desvelar a essência da realidade, unificando em princípios metafísicos referentes aos processos mentais não conscientes. Neste sentido, a formação de um processo inconsciente postulada por Schopenhauer-Freud supõe uma teoria geral da natureza humana, na qual os desejos, a busca por prazer, indicam um papel primário, e a percepção da realidade um papel secundário (ZENTNER, 1995, p.2).

A busca de um estado transcendente está sempre renunciando aos desejos, e vivendo de forma cautelosa. Para trilhar este caminho da cautela, primeiramente, é preciso apreender este conhecimento ascético através do intelecto, embora Schopenhauer não sugira a utilização de sua filosofia para prática cotidiana. A negação dos desejos e a renúncias das volições fazem parte do domínio metafísico. A liberdade não é posta como uma realização de vários atos em conjunto com a tomada de decisões e escolhas individuais, mas sim negações de tais atos que poderiam possibilitar a objetivação da vontade, intervindo na raiz da cessão dos desejos. Schopenhauer parte para o campo da essência, portanto, diz respeito a um sujeito metafísico.

Para Freud, através do autoconhecimento proporcionado através da experiência clínica é possível cindir a série de repetição, resgatando um conteúdo do inconsciente para o consciente, e assim reduzindo o determinismo psíquico, aumentando a capacidade de escolhas, ou apenas reduzindo a repetição.

Mesmo com todas estas alternativas disponíveis, tanto para Freud quanto para Schopenhauer sempre terá um Eu primário determinando um Eu secundário. Isto devido às linhas de consistência que compõem os conceitos de vontade e de inconsciente, às quais tentamos traçar no presente artigo.

\section{Conclusões}

Mesmo que essa separação esquemática entre o pensamento de ambos autores seja plausível, é possível acrescentar mais elementos entre eles - e para o bem dessa relação. Com efeito, os conceitos postulados por Freud carregam em si sedimentos de outros conceitos que buscavam resolver outros problemas. Os componentes conceituais da metafísica serviram 
como elementos que permitiram a Freud arquitetar sua metapsicologia com a abstração e a profundidade que o levassem além das informações obtidas pelos dados empíricos, permitindo desenvolver os três pontos vista: tópico, econômico e dinâmico, em consonância com a intensidade preponderante que o inconsciente exerce sobre a consciência. Nesse sentido, a metapsicologia pode ser concebida como um conhecimento aberto que se modifica de acordo com as práticas clínicas, em que os conceitos têm a função de reestruturar a própria teoria psicanalítica; em contrapartida, a pretensão de Schopenhauer foi criar uma filosofia com o propósito de desvelar o enigma do mundo a partir da vontade e representação.

\title{
THE METAPHYSICAL SYSTEM OF SCHOPENHAUER AND THE METAPSYCHOLOGY OF FREUD: MEETINGS AND DISAGREEMENTS
}

\begin{abstract}
This article aims to analyze the plots and tensions between the emergence of Freud's psychoanalysis in contact with the philosophy of Schopenhauer. With the publication of psychoanalytic writings of Freud in his metapsychological stage the psyche began to be working for him in a new light, thus breaking with the classical psychology of his time. In turn, and in comparison, the metaphysical system adopted by Schopenhauer was designed to address the theorizing about a basic principle governing the universe, regardless of a necessarily practical use. Although psychoanalysis and philosophy have different goals, it is not yet known with philosophy's contribution depth in the construction of psychoanalytic theory developed by Freud, especially with regard to the agreements and disagreements that the prefix meta has metaphysics advocated by Schopenhauer and metapsychology Freud.
\end{abstract}

Key-words: Schopenhauer, Freud, metaphysics and metapsychology.

\section{EL SISTEMA METAFÍSICO EN SCHOPENHAUER Y LA METAPSICOLOGIA EN FREUD: ENCUENTROS Y DESACUERDOS}

\section{Resumen}

En este artículo se pretende analizar la trama y la tensión entre el surgimiento del psicoanálisis de Freud, en contacto con la filosofía de Schopenhauer. Con la publicación del escrito psicanalíticos de Freud en su etapa metapsicológica, la psique comenzó a ser trabajado para él bajo una nueva perspectiva, rompiendo así con el clásico de la psicología de su tiempo. A su vez, y comparativamente, el sistema metafísico aprobado por Schopenhauer, encaminadas a responder a la teorizó sobre un principio fundamental que gobierna el universo, independientemente del uso necesariamente la práctica. Aunque el psicoanálisis y la filosofía tiene diferentes objetivos, todavía no se conoce en profundidad el aporte de la filosofía en la construcción de la teoría psicoanalítica desarrollada por Freud, especialmente en cuanto a los acuerdos y desacuerdos que el prefijo meta se encuentra en la metafísica recomendado por Schopenhauer y la metapsychology de Freud.

Palabras clave: Schopenhauer, Freud, la metafísica, la metapsicologia. 


\section{Referências}

BIRMAN, Joel. Freud \& a filosofia. Rio de Janeiro: Jorge Zahar, 2003.

CAMPOS, Érico Viana. Primeira concepção freudiana de angústia: uma revisão crítica. Agora, Rio de Janeiro, v.7 n.1, Jul/Jan, 2004.

FULGENCIO, Leopoldo. As especulações metapsicológicas de Freud. Natureza Humana, v. 5, n. 1, p. 129-173, 2003.

FREUD, Sigmund. Obras psicológicas completas de Sigmund Freud. Direção da edição, Jayme Salomão. Rio de Janeiro: Imago, 1996. Vol. VI.

Obras psicológicas completas de Sigmund Freud. Direção da edição, Jayme Salomão. Rio de Janeiro: Imago, 1996. Vol. XIV.

GAY, Peter. Freud: uma vida para o nosso tempo. Editora Companhia das Letras, 2002.

GOMES, Gilberto. A Teoria Freudiana da Consciência1. Psicologia: Teoria e Pesquisa, v. 19, n. 2, p. 117-125, 2003.

IANNACO, Domenico. Schopenhauer e i pazienti della Charité di Berlino (1812-1813).IL Sogno della farfalla, Rivista di Psichiatria e Psicoterapia, Nuove Edizioni Romane: Roma, vol.4, 1998.

LOPARIC, Zejko. Além do inconsciente: sobre a desconstrução heideggeriana da psicanálise. Revista Natureza Humana, vol. 3, n.1, 2001.

PRADO, Caio. Metafísica e ciência: A vontade e a analogia em Schopenhauer. Revista Voluntas: Estudos sobre Schopenhauer - Vol. 6, No 1 p.44-84, 2015.

SCHOPENHAUER, Arthur. O mundo como vontade e representação. $2^{\mathrm{a}}$. ed.,Trad. M. S. Sá Correia. Rio de Janeiro: Contraponto, 2004. 
SCHOPENHAUER, Arthur. Fragmentos sobre a história da filosofia: precedido de esboço de uma história da doutrina do ideal e do real. São Paulo: Martins Fontes, 2007.

RAIKOVIC, Pierre. O Sono Dogmático de Freud. Trad. Teresa Resende. Rio de Janeiro: Zahar, 1996.

ROTHE-NEVES, R.; NEVES, A. Freud e o esquecimento em Die Flucht ins

Vergegessen, de Marcel Zentner. Psicologia: Reflexão e Crítica. vol.15, nº.2, 2002.

ZENTNER, Marcel. Die flucht ins vergessen: die anfänge der psychoanalyse freuds bei schopenhauer. Darmstald: Wissenschaftliche Buchgesellschaft, 1995.

Data de recebimento: 17/08/16

Data de aceite: 23/03/2017

\section{Sobre os autores:}

Mateus de Freitas Barreiro é mestre no Programa de Pós-graduação em Educação da Faculdade de Filosofia e Ciências, UNESP, campus de Marília/SP, na linha de pesquisa História e Filosofia da Educação. Atua nas áreas de Psicologia, Filosofia e Educação. Endereço Eletrônico: mateusfbb@gmail.com

Alonso Bezerra de Carvalho em 2007 fez pós-doutorado em Ciências da Educação na Universidade Charles de Gaulle, Lille, França. Atualmente é professor adjunto da Universidade Estadual Paulista Júlio de Mesquita Filho, no Departamento de Educação da Unesp/Assis e do Programa de Pós-Graduação em Educação da Unesp/Marília. Foi Professor Visitante na Universidade de Santiago do Chile (Chile - 2015). Tem experiência na área de Educação, com ênfase em Filosofia da Educação e Didática. Endereço Eletrônico: alonsoprofessor@yahoo.com 